\title{
Recomendaciones prácticas para el diagnóstico y tratamiento de la infección urinaria en el adulto (I)
}

\author{
Practical Recommendations for the Diagnosis and Treatment \\ of Urinary Tract Infection in Adults (I)
}

\author{
Laura Castelo Corral ${ }^{1}$, Germán Bou Arévalo, Pedro Llinares Mondéjar ${ }^{1}$ \\ ${ }^{1}$ Unidad de Enfermedades Infecciosas, ${ }^{2}$ Servicio de Microbiología. \\ Complexo Hospitalario Universitario A Coruña. Xerencia de Xestión Integrada de A Coruña. SERGAS. A Coruña
}

La infección urinaria (IU) es una infección muy frecuente tanto en el ámbito comunitario como en el hospitalario. Constituye por su frecuencia la segunda infección de origen extrahospitalario atendida en hospitales, y una de las más frecuentes infecciones de origen nosocomial $(21 \%),{ }^{1,2}$ estando con frecuencia asociada a sondaje vesical $(80 \%)$.

Asimismo, figura entre las primeras causas de ingreso y morbilidad en los servicios de Medicina Interna siendo responsable de un incremento de la estancia, los costes y la mortalidad en pacientes sondados. ${ }^{3}$

De todo lo anterior, se deriva la importancia de realizar un correcto diagnóstico y tratamiento de esta entidad. Lo que a priori puede resultar sencillo, se complica si tenemos en cuenta que bajo el término "IU" se engloban diversos síndromes clínicos, cuyo espectro de gravedad clínica es muy amplio y que adoptan características especiales en cada huésped. A ello se suma, el aumento de la prevalencia de resistencia a antibióticos, incluso en el medio extrahospitalario.

El tratamiento antibiótico empírico inicial deberá basarse en las características y situación de gravedad del paciente, el síndrome clínico y los patrones locales de sensibilidad; y en los resultados del antibiograma para el tratamiento de continuación definitivo.

Este documento no pretende ser una revisión exhaustiva de la IU, sino proporcionar de forma sencilla una serie de recomendaciones prácticas que faciliten su manejo en los distintos ámbitos de la actividad clínica diaria. Con este propósito, recordamos primero la clasificación de la IU y la microbiología implicada en este tipo de infecciones, para después abordar el diagnóstico y tratamiento antimicrobiano por síndromes y en determinadas situaciones especiales.

En esta primera parte, se han incluido los apartados relativos a generalidades, cistitis, pielonefritis e infecciones recurrentes. En el próximo número, se revisará el manejo de la bacteriuria asintomática, prostatitis y candiduria, y la infección en el paciente sondado y el embarazo.

\section{Clasificación}

Distinguimos entre infecciones del tracto urinario complicadas y no complicadas en base a la presencia 0 ausencia de anormalidades funcionales 0 anatómicas del tracto urinario, factores del huésped y el patrón de resistencia antimicrobiana del uropatógeno:1,4-8

a) NO COMPLICADAS: mujeres sanas, premenopáusicas, no gestantes, sin comorbilidad, defectos estructurales del tracto urinario ni trastorno de la función renal.

b) COMPLICADAS:

- Sepsis grave.

- Riesgo de colonización asintomática del riñón:

- Varones.

- Mayores de 65 años.

- Gestación.

- Clínica de más de 1 semana de evolución.

- Infección por Proteus spp.

- Riesgo de microorganismos inusuales o resistentes:

- Sondaje vesical.

- Uropatía (litiasis, anomalía anatómica o anomalía funcional).

- Antibioterapia reciente.

- Infección nosocomial u hospitalización reciente.

- Manipulación urológica reciente.

- IU previa en el último mes o recurrente ( $\geq 3$ en 1 año $0 \geq$ 2 en 6 meses).

- Diabetes mellitus.

- Insuficiencia renal crónica.

- Inmunodepresión severa.

\section{Microbiología}

a) Etiología:

La etiología de la IU varía dependiendo del tipo de infección, el ámbito de adquisición y la presencia de factores predisponentes.

La mayoría de los episodios están producidos por microorganismos procedentes del colon por lo que es la microbiota fecal del paciente la que condiciona la etiología. En el resto de los casos, la infección es de origen exógeno, por microorganismos introducidos en la vía urinaria durante su manipulación. ${ }^{9}$ La pielonefritis de origen hematógeno es rara y suele estar producida por Staphylococcus aureus y levaduras. ${ }^{4,10}$ 
La infección es monomicrobiana en más del 95\% de los casos; puede ser polimicrobiana en pacientes con sonda vesical permanente, manipulación urológica reciente, vejiga neurógena o fístula vesicointestinal 0 vesicovaginal. ${ }^{4}$ En el resto de los casos, el aislamiento de más de un microorganismo suele corresponder a una contaminación, especialmente si encontramos Lactobacillus spp. o Propionibacterium spp..$^{5}$

La IU no complicada está causada en más del $80 \%$ por Escherichia coli, y con menor frecuencia por otras enterobacterias (Klebsiella spp.)., ${ }^{4,10}$ En la IU complicada, aunque E. coli sigue siendo el agente más común (40\%), ${ }^{4}$ aumenta la incidencia de infección por otras enterobacterias (Klebsiella spp., Serratia spp., Enterobacter spp., Proteus spp., Morganella spp....), y por otros micoorganismos como Enterococcus spp., Pseudomonas spp., Staphylococcus spp. y Candida spp.. ${ }^{9}$ Por otra parte, aumenta la frecuencia de patógenos con susceptibilidad reducida a antimicrobianos. Son factores de riesgo de infección por microorganismos resistentes: la antibioterapia previa, la hospitalización y manipulación urológica recientes, y el sondaje uretral. ${ }^{4}$ En el paciente sondado, son relativamente frecuentes Pseudomonas aeruginosa, Staphylococcus spp. y levaduras.

Proteus spp. está provisto de flagelos que le permiten avanzar contracorriente y alcanzar la pelvis renal. Por este motivo, su aislamiento en orina indica con frecuencia que existe infección renal. Además, puede producir ureasa que alcaliniza la orina favoreciendo la precipitación de sales de estruvita y apatita con la consiguiente aparición de litiasis (coraliforme). La infección por Proteus spp. es más frecuente en ancianos y portadores de sonsa vesical permanente. ${ }^{4}$

Staphylococcus saprophyticus produce el $10 \%$ de las cistitis no complicadas en mujeres jóvenes durante el verano. El resto de los estafilococos coagulasa negativo pueden causar infección en pacientes con instrumentalización urinaria, especialmente sondas permanentes. ${ }^{4,10}$

$S$. aureus puede producir infección por vía ascendente en pacientes con sonda vesical; en los demás casos, su aislamiento en orina suele indicar una infección renal secundaria a bacteriemia de cualquier origen, con posible desarrollo de absceso renal. 4,5

Enterococcus spp. se aísla especialmente en ancianos con hipertrofia prostática, en postoperados y en pacientes que llevan sonda vesical permanente 0 han recibido profilaxis 0 tratamiento con una cefalosporina 0 aztreonam. ${ }^{4}$

Candida spp. puede invadir el riñón por vía hematógena en pacientes que presentan neutropenia prolongada, reciben nutrición parenteral, tratamiento con corticoides 0 antibióticos de amplio espectro., ${ }^{4,5} \mathrm{La}$ infección del riñón suele ser bilateral y cursa con la presencia de microabscesos múltiples en corteza y médula. La afección vascular puede causar necrosis papilar y las papilas desprendidas sirven como nido para la formación de bolas fúngicas. La infección por vía ascendente es menos frecuente, suele respetar la corteza renal y ser unilateral. Su curso es subagudo 0 crónico y los signos de infección sistémica, como la fiebre, suelen estar ausentes. ${ }^{11}$ Pueden formarse bolas fúngicas 0 abscesos perinefríticos. Estas infecciones ocurren casi exclusivamente en pacientes con diabetes 0 con anormalidades anatómicas de la vía urinaria., ${ }^{4,5}$

b) Resistencia antimicrobiana de los patógenos urinarios:

En España la prevalencia de cepas de E. coli resistentes a ampicilina y cotrimoxazol es muy alta, por encima del $60 \%$ y $30 \%$ respectivamente. ${ }^{3,12}$ Asimismo, se ha constatado un descenso de la sensibilidad a fluorquinolonas con tasas de

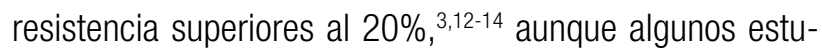
dios han mostrado porcentajes bajos $(<10 \%)$ en mujeres jóvenes con cistitis no complicada. ${ }^{12,14}$ En cuanto a amoxicilina-clavulánico y cefuroxima, están apareciendo estudios con resistencias de hasta el $25 \%$ en algunas comunidades autónomas. ${ }^{3,12}$ Las tasas de resistencia más bajas corresponden a fosfomicina $(<3 \%)$, seguida de nitrofurantoína y cefalosporinas de tercera generación. ${ }^{3,12-14}$

Por otra parte, en los últimos años se ha observado un aumento progresivo de las IUs extrahospitalarias producidas por cepas de E. coli portadoras de betalactamasas de espectro extendido (BLEEs), que ya representan más del $5 \%$ de los aislamientos a nivel nacional., 3,13,15,16 Son más frecuentes en infecciones en pacientes ancianos, institucionalizados, con comorbilidad (diabetes, hepatopatía crónica), IUs de repetición, uropatía subyacente, hospitalización previa y/o antibioterapia reciente, especialmente cefalosporinas y fluorquinolonas. ${ }^{15-17}$ Las BLEEs son enzimas inducibles que hidrolizan las cefalosporinas de tercera y cuarta generación, la cefuroxima y el aztreonam. A la resistencia intrínseca a betalactámicos, se suma con frecuencia una resistencia cruzada a quinolonas y cotrimoxazol, lo que representa un importante problema terapéutico. Los carbapenemes muestran una elevada estabilidad frente a la hidrólisis y un escaso efecto inóculo por lo que son el fármaco de primera elección en infecciones moderadasgraves. ${ }^{17,18}$ Fosfomicina mantiene su sensibilidad y actividad frente a E. coli BLEE por lo que sería de elección en el tratamiento de las infecciones bajas. ${ }^{17}$

\section{Diagnóstico}

\section{a) Síndrome clínico}

- Cistitis: síndrome miccional (disuria, polaquiuria, micción urgente), dolor suprapúbico y orina maloliente, y en ocasiones hematuria. En la mujer y anciano es relativamente frecuente la incontinencia urinaria., ${ }^{1,19}$

- En la mujer con síndrome miccional se plantea el diagnostico diferencial con la uretritis y la vaginitis (tabla 1).4,6,19,20 
Tabla 1. Causas de síndrome miccional en la mujer

\begin{tabular}{|c|c|c|c|}
\hline \multicolumn{4}{|c|}{ Diagnóstico diferencial del síndrome miccional en la mujer } \\
\hline Causa & Piuria & Urocultivo & Otras características \\
\hline Cistitis/ pielonefritis aguda & + & + & - Síndrome cístico de inicio repentino. Ver texto \\
\hline Uretritis infecciosa & + & - & 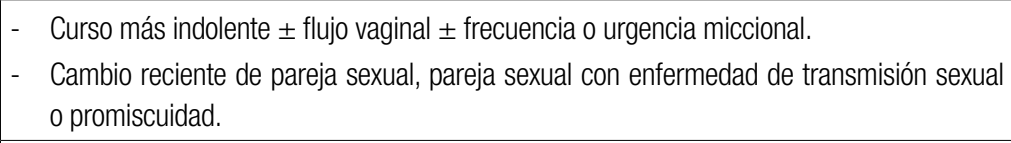 \\
\hline Uretritis no infecciosa & - & - & $\begin{array}{l}\text { - Picazón o flujo vaginal. } \\
\text { - } \text { Actividad sexual no infrecuente; posible exposición a productos químicos o alérgenos } \\
\text { (productos de baño o ducha, productos de higiene íntima, espermicidas). } \\
\text { - } \quad \text { Diagnóstico de exclusión. }\end{array}$ \\
\hline Vaginitis & - & - & $\begin{array}{l}\text { - } \quad \text { Flujo vaginal, olor desagradable, dispareunia. Disuria "externa" (al contactar la orina con } \\
\text { las superficies vulvares epiteliales inflamadas). } \\
\text { - } \quad \text { Posible nueva pareja sexual o relaciones sexuales sin protección; historia de vaginitis. }\end{array}$ \\
\hline
\end{tabular}

- Pielonefritis aguda (PNA): además del síndrome cístico, se producen manifestaciones locales, como el dolor lumbar, y sistémicas, como fiebre y escalofríos, que son las que la diferencian de la cistitis. En el ancianos los síntomas suelen ser sutiles 0 atípicos y puede cursar con caídas al suelo, confusión, postración y dolor abdominal con escasa fiebre 0 sin ella. ${ }^{1,19}$

- Prostatitis aguda: cuadro febril agudo, de inicio brusco, caracterizado por dolor lumbar bajo, dolor perineal, síndrome cístico y afectación del estado general. Puede causar retención aguda de orina. El tacto rectal revela una próstata aumentada de tamaño, inflamada y muy dolorosa., ${ }^{4,21}$

- Prostatitis crónica: clínica de infección urinaria (o bacteriuria) recidivante por el mismo microorganismo. Entre los episodios de infección sintomática, el paciente puede presentar síntomas locales inespecíficos de afectación de órgano pelviano (dolor referido al periné, testículos, punta del pene, parte baja de la espalda...) o un grado variable de síntomas irritativos locales. ${ }^{4,21}$

\section{b) Análisis de sangre}

Está indicado en todos los casos excepto en la cistitis. ${ }^{4-6,20}$

\section{c) Análisis de orina}

\section{Detección de piuria:}

La piuria se puede detectar mediante:

- Prueba de la esterasa leucocitaria. Se determina mediante una tira reactiva que vira a color azul en 1-2 minutos. Tiene una sensibilidad del $75-96 \%$ y una especificidad del 94-98\% ${ }^{1,10,19}$ Puede arrojar falsos positivos en muestras contaminadas por flujo vaginal o Trichomonas vaginalis $\mathrm{y}$, falsos negativos en muestras con niveles altos de glucosa, proteínas, ácido ascórbico 0 ácido oxálico. ${ }^{10}$

- Recuento de leucocitos en cámara cuentaglóbulos. Se considera indicativo de piuria el hallazgo de más de 10 leucocitos/ $\mu \mathrm{l} .1,4,5,10$

- Examen del sedimento de orina. Se considera indicativo la presencia de más de 5 leucocitos por campo (x 40). Tiene un margen de error superior al del recuento en cámara cuentaglóbulos aunque cuando la piuria es importante, el error es insignificante. ${ }^{1,4}$

La leucocituria puede faltar en caso de obstrucción, neutropenia o si el pH es alcalino (infección por microorganismos productores de ureasa como Proteus spp. o Corynebacterium urealyticum). ${ }^{4,5}$

Su presencia no es específica de IU; puede verse en el 30$50 \%$ de la población anciana en ausencia de bacteriuria y en otras patologías (nefritis intersticial, litiasis, malignidad urotelial, uretritis). ${ }^{1,4,19}$

\section{Detección de bacteriuria.}

Se puede llevar a cabo la detección de bacteriuria mediante:

- Detección de nitritos: cuando las bacterias presentes en la orina son capaces de reducir los nitratos a nitritos. Si la orina tiene nitritos, la tira reactiva vira a color rosa en 1 minuto. Su capacidad está limitada a la presencia de microorganismos pertenecientes a la familia Enterobacteriaceae. No es útil en casos de infección por cocos Gram positivos (Enterococcus spp. 0 S. saprophyticus), Pseudomonas spp., Acinetobacter spp. y Candida spp., los cuales no producen nitrato reductasa. $^{10}$

- La positividad de la prueba es altamente específica de bacteriuria (> 90\%) pero la técnica es poco sensible $(50 \%)$ en base a lo comentado. ${ }^{10,19}$ Además, puede dar lugar a falsos negativos si la densidad de gérmenes es baja $\left(<10^{3} \mathrm{UFC} / \mathrm{ml}\right)$ 0 el tiempo de permanencia en la vejiga ha sido corto. 19,20,22

- Detección de bacteriuria por microscopía. La bacteriuria se puede detectar mediante microscopía usando observación en fresco o mediante tinción de Gram. ${ }^{22}$

- La tinción de Gram de la orina sin centrifugar suministra información inmediata sobre la naturaleza de la infección y consecuentemente sirve de guía a la hora de seleccionar el tratamiento empírico., ${ }^{4,10}$ Así por ejemplo, si en el Gram se observan cocos gram positivos (CGP) en cadenas, la antibioterapia debe incluir un antimicrobiano activo frente a 
Enterococcus spp. Sin embargo, tiene el inconveniente de que su sensibilidad es baja para concentraciones por debajo de $10^{5} \mathrm{UFC} / \mathrm{ml}$, lo que la invalida en el diagnóstico de la IU no complicada donde recuentos entre $10^{2}$ y $10^{4} \mathrm{UFC} / \mathrm{ml}$ son frecuentes. ${ }^{10,22}$

- Detección de bacteriuria o bacteriuria y piuria mediante sistemas automáticos. Existen en el mercado diferentes sistemas que, mediante citometría, permiten cribar rápidamente las orinas con bacteriuria y/o piuria significativa y seleccionarlas para realizar cultivo convencional. ${ }^{9}$

\section{d) Cultivo de orina}

En la mujer joven con cistitis extrahospitalaria no complicada de menos de 1 semana de evolución no es necesario realizar urocultivo, a no ser que la IU sea una recidiva precoz (primer mes). 4,6,8,20 En las demás circunstancias, 1,4,5,20,23 se debe practicar siempre un urocultivo inicial y se recomienda realizar otro de control a las 1-2 semanas de finalizar el tratamiento antibiótico. En pacientes con pielonefritis es aconsejable realizar un segundo urocultivo a las 72 horas de tratamiento, sobre todo, si persiste la fiebre, existe insuficiencia renal avanzada o se trata de una infección complicada. ${ }^{4,5,19}$

\section{Obtención, transporte y conservación de muestras:}

El urocultivo se realiza preferentemente con una muestra de orina de primera hora de la mañana. ${ }^{10}$ Sin embargo, si hay indicación de iniciar la antibioterapia, debemos recoger la muestra antes de la primera dosis de antibiótico sin retrasar el inicio del tratamiento al día siguiente. No se debe forzar la ingesta de líquidos para que el paciente realice la micción ya que una toma excesiva de líquidos diluye la orina y disminuye el recuento de colonias por ml. ${ }^{10}$

La mayor parte de las muestras en adultos se obtienen por micción espontánea; se recoge la orina de la mitad de la micción para reducir la contaminación de la muestra con bacterias de la flora uretral. ${ }^{19}$ Aunque clásicamente se ha insistido en la importancia de realizar una limpieza exhaustiva de los genitales externos antes de la recogida de la orina, se ha demostrado que en mujeres este lavado no disminuye la contaminación de la muestra y que el punto realmente importante es la obtención de la muestra sin que la orina entre en contacto con los genitales externos. ${ }^{24,25}$

- Desechar la primera parte de micción (orina uretral).

- Recoger la micción media, sin interrumpir el flujo de orina, utilizando un recipiente de plástico estéril, de boca ancha, y posteriormente cerrarlo herméticamente.

- En mujeres, evitar la recogida durante la menstruación.

El transporte al laboratorio debe realizarse en las primeras 2 horas tras su recogida ${ }^{22}$. Si no es posible, debe conservarse en la nevera a $4{ }^{\circ} \mathrm{C}^{19}$.

La muestra de orina puede también obtenerse directamente de la vejiga mediante:
Sondaje vesical: evita la posible contaminación con la flora uretral. Sin embargo, puede introducir microorganismos en la vejiga y producir una IU iatrogénica. Sólo se considera indicado cuando no es posible obtener muestra por micción media, como es el caso de pacientes inmovilizados, obesos, con alteraciones neurológicas, niños, etc. 22,25 Una vez introducida la sonda, se desechan los 15-30 ml iniciales recogiendo el flujo siguiente en un recipiente estéril. ${ }^{10}$

Punción suprapúbica: es preferible para el diagnóstico cuando los resultados de los cultivos por otros métodos son de difícil interpretación 0 cuando se sospechan bacterias anaerobias como causa de infección. ${ }^{10}$ Resulta especialmente útil y fácil de realizar en niños. Estas muestras están exentas de contaminación y cualquier hallazgo microbiológico debe considerarse significativo. ${ }^{19,25}$ Antes de realizar la punción se debe asegurar que la vejiga esté llena y se pueda palpar, después desinfectar la zona de la piel y proceder a la punción y aspiración con una aguja o jeringuilla. Se transfiere la orina a un tubo estéril o a un recipiente con medio de transporte para anaerobios. ${ }^{10}$

En determinadas circunstancias, la muestra de orina debe ser recogida de forma especial:

- Pacientes con sondaje vesical permanente: nunca se debe recoger la orina de la bolsa colectora. ${ }^{10,25} \mathrm{Si}$ el paciente lleva un sistema de drenaje cerrado, el urocultivo se recoge sin abrir el circuito, puncionando el dispositivo pertinente 0 en su defecto, la sonda. Se desinfecta el cono de la sonda con etanol al 70\%. Con aguja y jeringa, se pincha y aspira de 3-10 $\mathrm{ml}$ de orina que se introducen en un frasco de boca ancha estéril. ${ }^{10}$

- Pacientes con nefrostomía: se procede como en el caso del sondaje permanente pero introduciendo la orina en un recipiente con medio de transporte para anaerobios. ${ }^{10}$

- Pacientes con conducto ileal: se debe quitar el dispositivo externo y limpiar el estoma con etanol al 70\%, seguido de povidona iodada y eliminar esta limpiando de nuevo con alcohol. Una vez limpio el estoma, se introduce una sonda doble más allá de la fascia y se recoge la orina que se transfiere a un tubo estéril. ${ }^{10}$

\section{Criterios diagnósticos:}

Se consideran significativos recuentos de $\geq 10^{5} \mathrm{UFC} / \mathrm{ml}$ en la mayoría de las muestras de orina. $4,7,9,20$ Sin embargo, en determinadas circunstancias se admite la existencia de IU con recuentos muy inferiores como son:4,7-9,20

- En orinas obtenidas por punción suprapúbica 0 que proceden del riñón, cualquier recuento es indicativo de infección.

- En mujeres jóvenes con síndrome miccional y leucocituria, se considera significativo un recuento de $\geq 10^{2} \mathrm{UFC} / \mathrm{ml}$.

- En varones en los que la obtención de orina es menos susceptible de contaminarse, son significativos recuentos de $\geq$ $10^{3} \mathrm{UFC} / \mathrm{ml}$. 
- En orinas obtenidas por sondaje vesical, es significativo un recuento de $\geq 10^{3} \mathrm{UFC} / \mathrm{ml}$ de cualquier microorganismo en cultivo puro.

El urocultivo puede ser negativo o tener recuentos bajos en caso de:4,7 a) tratamiento antibiótico previo; b) micción reciente, a menudo secundaria al síndrome cístico; c) obstrucción ureteral o infecciones que no comunican con la orina excretada; d) pH urinario muy bajo; e) infección por un microorganismo "exigente" 0 de crecimiento lento (Chlamydia trachomatis, Mycoplasma hominis, Ureaplasma urealyticum o Mycobacterium tuberculosis).

\section{e) Hemocultivos}

Deben solicitarse en todos los casos de pielonefritis aguda y prostatitis aguda. ${ }^{1,4,5}$ Alrededor de un $20-30 \%$ de los pacientes con pielonefritis tienen bacteriemia. ${ }^{6}$ La identificación del microorganismo por hemocultivo puede ser útil en casos en los que se inicia el tratamiento antibiótico antes de recoger la muestra de orina y en aquellos en los que el urocultivo resulta finalmente contaminado.

\section{f) Estudio radiourológico}

Las pruebas de imagen con carácter urgente (ecografía/ TC) están sólo indicadas en casos de pielonefritis o prostatitis aguda que cursen con shock séptico, insuficiencia renal aguda, clínica de complicación local o fiebre persistente tras 72 horas de tratamiento antimicrobiano correcto., ${ }^{4,5,26}$ La TC con contraste es más sensible que la ecografía para identificar abscesos de pequeño tamaño y áreas de nefritis local. ${ }^{19,26}$ La radiografía simple de abdomen tiene un papel limitado pero todavía está indicada en casos de sospecha de urolitiasis (dilatación del sistema pielocalicial objetivada en la ecografía sin que se detecte un cálculo $)^{26} 0$ pielonefritis enfisematosa (pielonefritis grave en un paciente diabético). ${ }^{19}$

El estudio morfológico y/o funcional de las vías urinarias (ecografía renovesical, pielografía intravenosa con placa postmiccional y/o uro-TC) puede llevarse a cabo una vez resuelto el episodio agudo. La realización de la pielografía intravenosa debe retrasarse hasta 2-4 semanas después del episodio. Las indicaciones para el estudio radiourológico programado son las siguientes:

- Mujeres con infección recurrente o sospecha de patología urológica (dolor cólico, dificultad en la micción, hematuria, incontinencia, litiasis, infección por Proteus spp..)., ${ }^{4,5}$

- Todos los varones, excepto si se trata de un episodio aislado de cistitis en un varón joven sin clínica sugestiva de patología urológica. ${ }^{6,23}$ La mayoría de infecciones urinarias en hombres ocurren en asociación con otras condiciones como enfermedades de transmisión sexual, retención urinaria, prostatitis, defectos anatómicos urológicos o instrumentación del tracto urinario. Si el estudio de imagen está indicado y es normal, en ausencia de otro factor predisponente, hay que descartar prostatitis crónica.

\section{Cistitis aguda}

El manejo de la cistitis es siempre ambulatorio. En la tabla 2 se muestra la antibioterapia empírica recomendada teniendo en cuenta las resistencias a antimicrobianos en nuestro medio. ${ }^{1,4,5,8,27,28}$

$\mathrm{Si}$ el diagnóstico diferencial entre cistitis y pielonefritis no es del todo claro (fiebre subjetiva, duración prolongada (> 5-7 días), dolor vago en flanco...), evitar fosfomicina y nitrofurantoína porque no alcanzan niveles adecuados en tejido renal. ${ }^{20,29}$

En las cistitis complicadas, una vez conocido el resultado del urocultivo, se debe adecuar el tratamiento a la sensibilidad del microorganismo aislado dando preferencia a las fluorquinolonas o cotrimoxazol por su espectro más selectivo, su baja tasa de recurrencia y en el varón, su mayor penetración prostática. ${ }^{27,29}$

Tabla 2. Tratamiento empírico de la cistitis

\begin{tabular}{|c|c|c|}
\hline \multicolumn{3}{|c|}{ Cistitis no complicada } \\
\hline \multicolumn{3}{|c|}{ De elección Fosfomicina trometamol: monodosis de $3 \mathrm{~g}$. } \\
\hline \multirow{3}{*}{ Alternativo } & $\begin{array}{l}\text { Ceftibuteno } 400 \text { mg/d } \\
\text { Cefditorén } 200 \text { mg/12h }\end{array}$ & \multirow{2}{*}{ 3-5 días } \\
\hline & $\begin{array}{l}\text { Ciprofloxacino } 500 \text { mg/12h } \\
\text { Levofloxacino } 500 \text { mg/24h }\end{array}$ & \\
\hline & Nitrofurantoína 100 mg/12h & 5-7 días \\
\hline \multicolumn{3}{|c|}{ Cistitis complicada ${ }^{1,2}$} \\
\hline \multicolumn{2}{|c|}{$\begin{array}{l}\text { Fosfomicina trometamol: una dosis de } 3 \mathrm{~g} \text { cada } 72 \mathrm{~h} \text {. } \\
\text { Ceftibuteno } 400 \mathrm{mg} / \mathrm{d} \\
\text { Cefditorén } 200 \mathrm{mg} / 12 \mathrm{~h}\end{array}$} & 7-10 días \\
\hline
\end{tabular}

1. En caso de factores de riesgo de BLEEs, utilizar fosfomicina.

2. Cuando en el Gram de orina se identifiquen cocos gram positivos (CGP), emplear amoxicilina-clavulánico 500/125 cada 8h.

\section{Pielonefritis aguda}

\section{a) Criterios de ingreso hospitalario:}

La mujer joven, no embarazada, sin enfermedad de base y sin afectación importante del estado general puede tratarse en régimen domiciliario (siempre que no existan dudas en el diagnóstico y la situación social permita asegurar el cumplimiento terapéutico). En el resto de los pacientes, se recomienda administrar una primera dosis de antibiótico por vía parenteral y vigilar la respuesta clínica durante 6-24 horas. Si el paciente no cumple criterios de ingreso, se mantiene estable y el estado general es bueno, se continua el tratamiento por vía oral de forma ambulatoria como se indica en la tabla $3.1,4,5,8,27,28,30$ Son criterios de ingreso hospitalario los siguientes: 4,6 
- Sepsis grave.

- Clínica de complicación local: dolor intenso, hematuria franca, masa renal...

- Insuficiencia renal aguda.

- Factores de riesgo de microorganismo resistente.

- Comorbilidad: anciano, diabetes, cirrosis, neoplasia, trasplante...

- Embarazo.

- Imposibilidad para cumplir tratamiento oral: vómitos, distocia social...

- Los que no se estabilicen tras 6-12 horas de observación una vez iniciado el tratamiento antibiótico. b) Indicaciones para realizar ecografía/TC abdominal urgente:

Como se ha señalado arriba, está indicado realizar una prueba de imagen urgente en las siguientes situaciones: $4,5,19,26$

- Shock séptico.

- Clínica de complicación local.

- Insuficiencia renal aguda.

- Fiebre persistente al tercer día de tratamiento correcto.

\section{c) Antibioterapia:}

Las recomendaciones para el tratamiento empírico se recogen en la tabla 3. 1,4,5,8,27,28,30 En todas las pautas, a partir de

Tabla 3. Tratamiento empírico de la pielonefritis aguda

\begin{tabular}{|c|c|}
\hline PNA sin criterios de ingreso & $\begin{array}{l}\text { a) Todo el ciclo por vía oral } 0 \\
\text { b) Monodosis de ceftriaxona* } 2 \mathrm{~g} \text { IV y observación 6-24h. *Alternativas (considerar resistencias locales): } \\
\text { aminoglucósido IV/IM, fluorquinolona IV. } \\
\text { Si se mantiene estable, completar tratamiento por vía oral de forma ambulatoria: } \\
\text { De elección: } \\
\text { - Ceftibuteno 200-400 mg/12h V0 } \\
\text { - Cefditorén } 200-400 \mathrm{mg} / 12 \mathrm{~h} \text { V0 } \\
\text { - Cefixima } 200 \mathrm{mg} / 12 \mathrm{~h} \text { V0 } \\
\text { Alternativas: } \\
\text { - Aminoglucósido IM dosis única diaria } \\
\text { - Ciprofloxacino } 500-750 \mathrm{mg} / 12 \mathrm{~h} \text { V0 } \\
\text { - Levofloxacino } 500 \mathrm{mg} / 24 \mathrm{~h} \text { V0 } \\
\text { Si CGP en orina: amoxicilina-clavulánico } 875 / 125 \mathrm{mg} / 8 \mathrm{~h} \text { V0. }\end{array}$ \\
\hline $\begin{array}{l}\text { PNA con criterios de ingreso, } \\
\text { y sin riesgo enterococo ni } \\
\text { microorganismo resistente }{ }^{1}\end{array}$ & $\begin{array}{l}\text { Ertapenem² } 1 \mathrm{~g} / 24 \mathrm{~h} \text { IV ó Ceftriaxona } 2 \mathrm{~g} / 24 \mathrm{~h} \text { IV } \\
\text { Si CGP en orina: } \\
\text { - Amoxicilina-clavulánico } 1-2 \mathrm{~g} / 8 \mathrm{~h} \text { IV } \\
\text { - Piperacilina-tazobactam } 4 \mathrm{~g} / 500 \mathrm{mg} / 8 \mathrm{~h} \mathrm{IV} \\
\text { En alérgicos a betalactámicos: } \\
\text { - Amikacina IV dosis única } \pm \text { fosfomicina sódica ( } 4 \mathrm{~g} / 8 \mathrm{~h}) \text { IV } \\
\text { - Si CGP en orina: vancomicina, teicoplanina, daptomicina ( } 6 \mathrm{mg} / \mathrm{kg} / 24 \mathrm{~h} \mathrm{IV})^{3} \text { o linezolid (600 mg/12 IV o V0). }\end{array}$ \\
\hline $\begin{array}{l}\text { PNA con criterios de ingreso, } \\
\text { y riesgo de infección por } \\
\text { microorganismo resistente } 0 \\
\text { inestabilidad hemodinámica }\end{array}$ & $\begin{array}{l}\text { Imipenem o meropenem 0,5-1 g/6-8h IV ó } \\
\text { Piperacilina-tazobactam } 4 \text { g/500 mg/6-8h IV } \\
\text { Si shock séptico añadir amikacina } 15-20 \text { mg/kg/24h IV } \\
\text { En alérgicos a betalactámicos utilizar la asociación de amikacina (15-20 mg/kg/24h) IV, con fosfomicina } \\
\text { sódica (4 g/8h) IV y un antibiótico activo frente a enterococo (vancomicina, teicoplanina, daptomicina } 0 \\
\text { linezolid). }\end{array}$ \\
\hline
\end{tabular}

1. Son factores de riesgo de microorganismos resistentes: la antibioterapia previa, hospitalización y manipulación urológica recientes, y el sondaje. Enterococcus sp se aísla especialmente en pacientes ancianos con hipertrofia prostática, postoperados, portadores de sonda permanente y aquellos que hayan recibido cefalosporinas 0 aztreonam.

2. Utilizar ertapenem en pacientes en los que se identifique algún factor de riesgo de BLEEs (edad avanzada, residencia, diabetes, hepatopatía, IUs de repetición, uropatía, ingreso reciente, antibioterapia previa).

3. Valorar dosis mayores $(8-10 \mathrm{mg} / \mathrm{kg}$ ) en infecciones graves o por microorganismos con CMl elevada. En pacientes con insuficiencia renal (CICr $<30)$, utilizar $6 \mathrm{mg} / \mathrm{kg}$ cada $48 \mathrm{~h}$. 
la defervescencia, el tratamiento puede continuarse por vía oral con un antibiótico elegido de acuerdo con el resultado del antibiograma, dando preferencia a las fluorquinolonas 0 al cotrimoxazol. 4,5,27,29 Habitualmente, se recomienda prolongarlo hasta completar 14 días de tratamiento. ${ }^{1,4,5}$ En mujeres con PNA no complicada se acepta acortar el tiempo de tratamiento, siempre y cuando el antimicrobiano utilizado sea una quinolona (7-10 días) 0 una cefalosporina (10 días). ${ }^{8,27,28}$ En pacientes con IU complicada y uropatía subyacente, la duración debe estar estrechamente relacionada con la resolución de ésta última, pudiendo ser preciso prolongar la antibioterapia hasta 21 días.

La persistencia de la fiebre a las $72 \mathrm{~h}$ de tratamiento 0 el empeoramiento clínico en cualquier momento puede deberse a la infección por un microorganismo resistente al antibiótico administrado 0 a la existencia de una complicación local:19,20,23 nefritis bacteriana aguda focal; colección supurada (absceso, quiste infectado, hidronefrosis o pionefrosis); necrosis papilar; o pielonefritis enfisematosa. Ante esta situación debemos solicitar un nuevo urocultivo y realizar una prueba de imagen del aparato urinario (ecografía y/o TC). Si se confirma una infección por un microorganismo resistente, se realizará tratamiento antibiótico parenteral específico hasta la defervescencia. En caso de existir una complicación local, suele estar indicado el tratamiento quirúrgico urgente (tabla 4) y el tratamiento antibiótico se prolonga durante al menos 3 semanas..$^{23,31-35}$ La suspensión del antibiótico se determinará por la respuesta clínica, la normalización de los marcadores de inflamación (VSG, PCR) y, la extensión y evolución radiológica de la infección.

\section{Respuesta terapéutica. IU recurrente}

Hay tres patrones de respuesta de la bacteriuria al tratamiento antibiótico: curación bacteriológica, infección no resuelta e infección recurrente. El recuento bacteriano en orina debe disminuir en las primeras 48 horas tras el inicio del antimicrobiano al cual el microorganismo es sensible. Si los títulos no disminuyen en este tiempo, el tratamiento fracasará con toda probabilidad. No obstante, como lo síntomas de IU son autolimitados, la clínica puede mejorar incluso aunque el tratamiento sea inefectivo.

\section{a) Curación bacteriológica:}

Es la negativización de los cultivos de orina que persiste después de haber finalizado el tratamiento antimicrobiano (habitualmente a las 1-2 semanas de suspenderlo). ${ }^{19}$

\section{b) Infección no resuelta:}

Se define como la persistencia de la bacteriuria tras 48-72 horas de tratamiento antimicrobiano adecuado. Puede ser debida $\mathrm{a}^{36}$

Infección por un microorganismo resistente al antimicrobiano empleado: Io más común es la colonización fecal por bacterias resistentes en un paciente que ha sido tratado recientemente con antibióticos. La segunda causa es el desarrollo de resistencia durante el curso del tratamiento. Otras menos frecuentes son la coinfección por un segundo patógeno resistente, que pasa desapercibido hasta que se trata el microorganismo dominante, o la reinfección precoz por una nueva especie resistente (sospechar fístula enterovesical).

Niveles del fármaco en orina por debajo de la concentración mínima inhibitoria del microorganismo: incumplimiento te-

Tabla 4. Indicaciones de tratamiento quirúrgico de la PNA con complicación local

\begin{tabular}{|c|c|}
\hline $\begin{array}{l}\text { Obstrucción ureteral con hidro/ } \\
\text { pionefrosis }\end{array}$ & $\begin{array}{l}\text { - } \quad \text { Indicado de forma urgente en todos los casos. } \\
\text { - } \quad \text { Cateterización ureteral retrógada o nefrostomía percutánea. }\end{array}$ \\
\hline Absceso renal & $\begin{array}{l}\text { - Indicado si absceso > } 5 \text { cm o absceso 3-5 cm que no mejora tras varios días de antibiótico } \\
\text { correcto. } \\
\text { - } \quad \text { Drenaje percutáneo. Si no es posible, drenaje quirúrgico ( } \pm \text { nefrectomía de rescate). }\end{array}$ \\
\hline Absceso perinefrítico & $\begin{array}{l}\text { - Indicado en todos los casos para diagnóstico microbiológico y tratamiento. } \\
\text { - } \quad \text { Drenaje percutáneo precoz. }\end{array}$ \\
\hline PNA enfisematosa & $\begin{array}{l}\text { - Indicado de forma urgente en todos los casos (excepto pielitis sin formación de absceso } \\
\text { ni obstrucción). } \\
\text { - Si el riñón es funcionante y la lesión no se extiende al espacio extrarrenal: drenaje percutá- } \\
\text { neo mediante nefrostomía } \pm \text { cateterización ureteral. } \\
\text { - Si la infección abarca todo el riñón, se extiende al espacio extrarrenal o no responde al } \\
\text { drenaje: nefrectomía. }\end{array}$ \\
\hline
\end{tabular}


Figura 1. Algoritmo diagnóstico-terapéutico de las infecciones recurrentes por recidiva

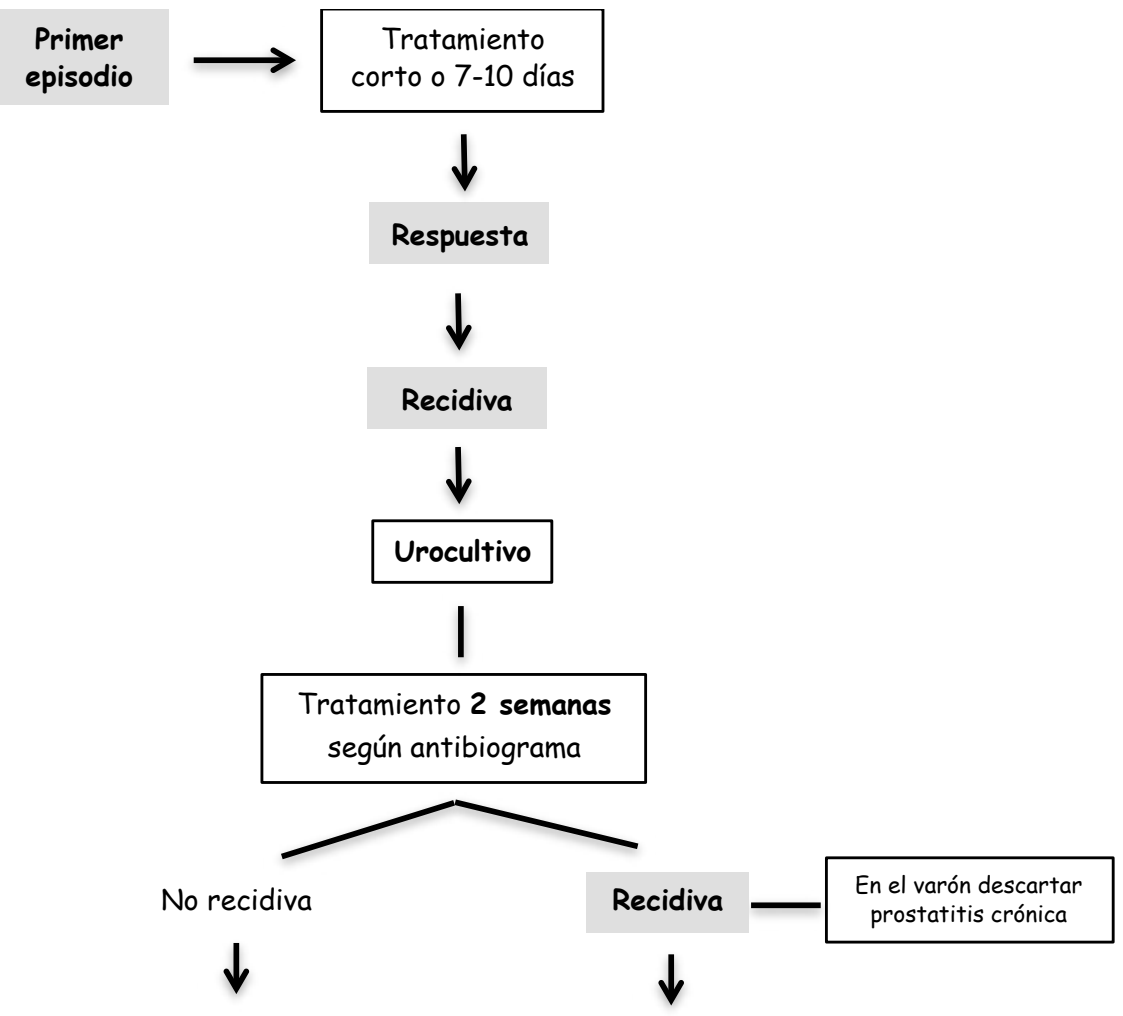

No tratar

Estudio urológico

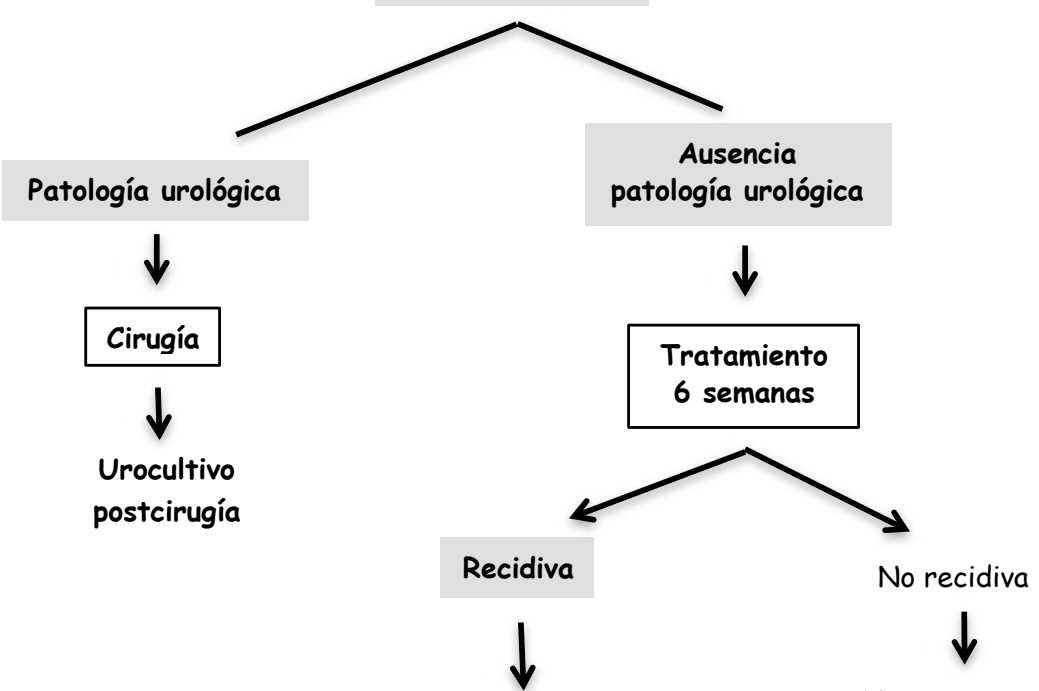

Considerar tratamiento supresivo* continuo (tabla 9)

* En embarazadas, pacientes con uropatía obstructiva no corregible con riesgo de lesión renal o pacientes con síntomas urinarios. 
rapéutico, dosis insuficiente, pobre absorción intestinal 0 pobre excreción renal (insuficiencia renal).

Carga bacteriana elevada dentro del tracto urinario, que contrarresta la actividad antimicrobiana. Lo más frecuente es una gran masa bacteriana asociada a un cálculo de gran tamaño.

\section{c) IU recurrente:}

Hablamos de infección recurrente cuando entre episodios se ha documentado la erradicación bacteriana mediante un urocultivo negativo. ${ }^{19,20,36} \mathrm{El}$ término recurrente se reserva para patrones de tres o más episodios de infección sintomática al año 0 dos o más episodios en seis meses. ${ }^{37}$

En la práctica habitual, no es infrecuente encontrar a un paciente que presenta bacteriuria tras la suspensión del tratamiento antibiótico sin que se disponga de urocultivo de control durante y después del tratamiento. Una alternativa para diferenciar entre infección no resuelta e infección recurrente es tratar de nuevo a estos pacientes y obtener cultivos durante y al final de la antibioterapia. ${ }^{36}$

Las infecciones recurrentes se clasifican en recidivas y reinfecciones.

\section{Recidivas:}

Representan el $20 \%$ de las recurrencias. ${ }^{4}$ Ocurren en las primeras semanas, habitualmente las dos primeras, tras la aparente curación de la IU. ${ }^{19}$ Son debidas a la persistencia de la cepa original en el foco de la infección, bien por la existencia de una anomalía genitourinaria 0 el acantonamiento de las bacterias en un lugar inaccesible al antibiótico (litiasis renal, absceso renal, prostatitis crónica), bien por un tratamiento inadecuado o demasiado corto (ancianos 0 pacientes con síndrome cistítico de más de 7 días de evolución que han sido tratados durante 3 días cuando en realidad se trataba de una pielonefritis poco sintomática). ${ }^{19,37}$ En la figura 1 se muestra el algoritmo de actuación. 1,4,19

\section{Reinfecciones:}

Suponen el $80 \%$ de las infecciones recurrentes. Habitualmente ocurren más de 2 semanas después de completar el tratamiento de la infección inicial. ${ }^{1,37}$ Están producidas por cepas distintas o por la misma cepa de la infección original, en cuyo caso el reservorio sería el tracto gastrointestinal 0 las propias células uroepiteliales. ${ }^{37}$ Los factores asociados a reinfección son los que se recogen en la tabla 5. 8,20,37

La figura 2 muestra las recomendaciones para el manejo de las reinfecciones. ${ }^{1,8,19,20,37,38}$ Las mujeres jóvenes sexualmente activas que padecen IU recurrentes excepcionalmente tienen anomalías del tracto genitourinario y el principal factor predisponente es el número de relaciones sexuales. Por dicho motivo, si no existe una historia sugestiva (antecedentes de cólico nefrítico, hematuria persistente tras la curación de la cistitis, sospecha de vejiga neurógena), no se aconseja realizar exploraciones radiourológicas en las cistitis, y sólo tras 2 episodios de pielonefritis. ${ }^{8,37}$ En mujeres postmenopáusicas los factores anatómicos o funcionales que afectan el vaciado de la vejiga urinaria son los que más se asocian a IU recurrente por lo que es recomendable realizar estudios para medir el residuo postmiccional. ${ }^{37} \mathrm{En}$ varones las reinfecciones se asocian casi siempre a una anomalía urológica y es obligado descartarla. 4,5,23

Algunas medidas generales, que aunque de dudosa eficacia, podrían recomendarse en un intento de reducir el

Tabla 5. Factores asociados a reinfección

\begin{tabular}{|c|c|}
\hline Mujeres sanas premenopáusicas & $\begin{array}{l}\text { - } \quad \text { Frecuencia de las relaciones sexuales } \\
\text { - } \quad \text { Uso de espermicidas } \\
\text { - } \quad \text { Pareja sexual nueva en el último año } \\
\text { - } \quad \text { Primera IU antes de los } 15 \text { años } \\
\text { - } \quad \text { Fenotipo no secretor1 }\end{array}$ \\
\hline Mujeres postmenopáusicas & $\begin{array}{ll}\text { - } & \text { Volumen urinario residual (vejiga neurógena) } \\
\text { - } & \text { Incontinencia urinaria } \\
\text { - } & \text { Prolapso genitourinario } \\
\text { - } & \text { Cirugía ginecológica previa } \\
\text { - } & \text { Fenotipo no secretor } \\
\text { - } & \text { Déficit de estrógenos } \\
\text { - } & \text { Antibioterapia de amplio espectro (anaerobicidas) }\end{array}$ \\
\hline Varones & - Anomalía urológica (adenoma de próstata con residuo) \\
\hline
\end{tabular}

1 Estas mujeres expresan en las membranas de sus células epiteliales dos globósidos que actúan como receptores para cepas uropatógenas de E. coli.

2 Condiciona una disminución de la concentración vaginal de Lactobacillus spp. y un aumento del pH vaginal que favorece la colonización vaginal y periuretral por enterobacterias.

3 Los betalactámicos (amoxicilina-clavulánico) son menos capaces de erradicar las enterobacterias de la flora colónica y vaginal, debido a que alcanzan concentraciones menores en estos lugares y a su efecto anaerobicida que facilita la persistencia del E. coli.

4 En el varón con IU recurrente, las recidivas a menudo son debidas a prostatitis crónica y las reinfecciones a una anomalía urológica. 
Figura 2. Algoritmo diagnóstico-terapéutico de las infecciones recurrentes por reinfección

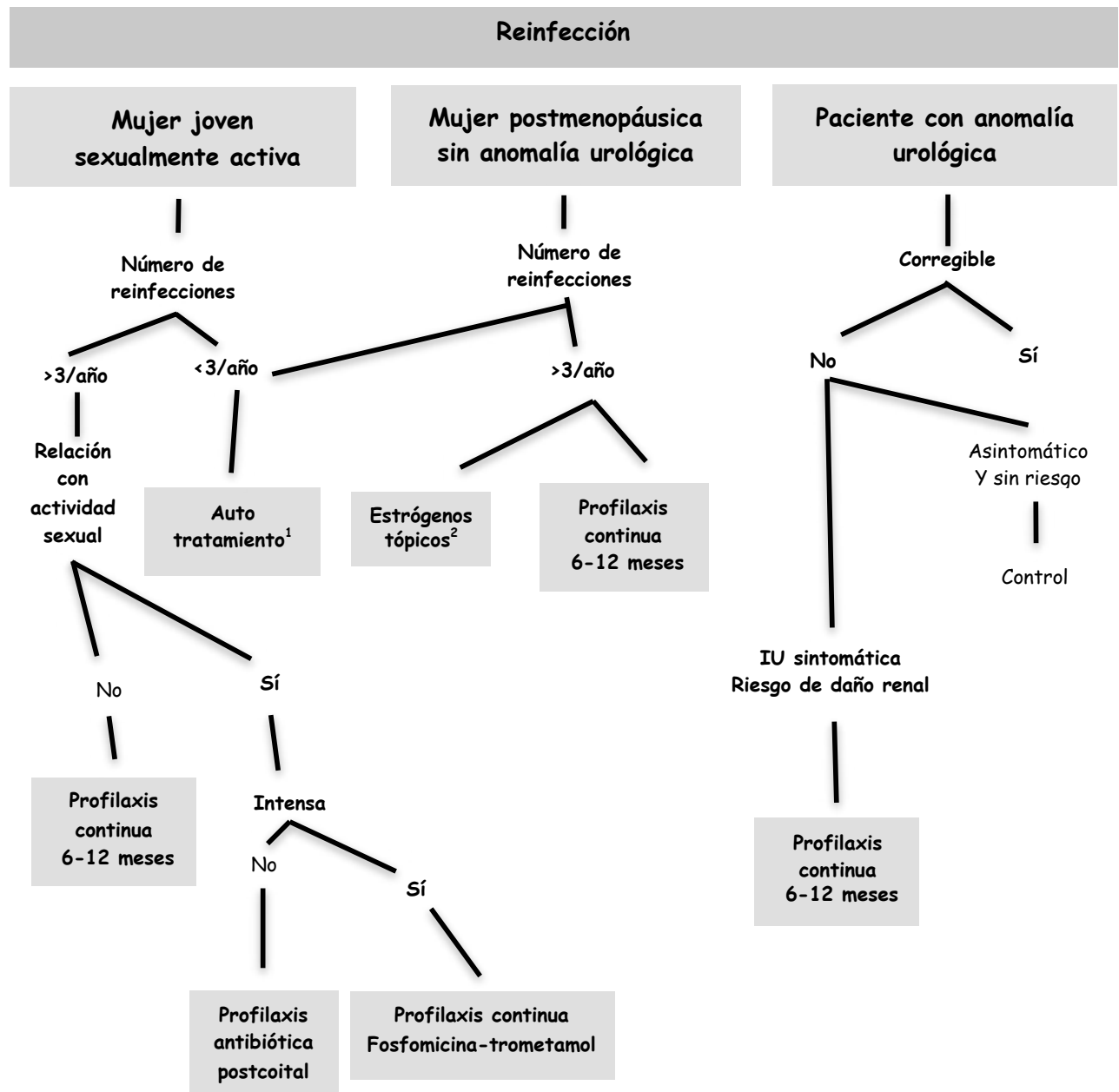

\footnotetext{
${ }^{1}$ Autotratamiento con monodosis de fosfomicina-trometamol cuando la paciente identifica síntomas sugestivos de cistitis.

${ }^{2}$ La administración de estrógenos por vía oral no reduce el número de IU ni previene las IU recurrentes.
}

riesgo de IU son: ingesta hídrica diaria de 2-3 litros, micción frecuente, micción postcoital, higiene anal hacia atrás, no emplear espermicidas ni diafragma, uso apropiado de compresas y tampones, y evitar ropa interior ajustada. ${ }^{8}$

\section{Profilaxis:}

La profilaxis antibiótica en sus distintas modalidades ha demostrado ser altamente efectiva en reducir el riesgo de IU recurrente. ${ }^{38}$ Debe iniciarse tras haber tratado la infección actual, una vez demostrada la negativización del urocultivo una o dos semanas después de la antibioterapia. Se recomienda emplear antimicrobianos no anaerobicidas en el tratamiento de los episodios de infección. La elección del antibiótico profiláctico se efectuará basándose en la historia previa de alergias y en los patrones de sensibilidad de las IU previas. ${ }^{37}$
Las pautas de profilaxis continua recogidas en la tabla 6 pueden utilizarse tanto en casos de recidiva como de reinfección. ${ }^{37,38}$ La toma de la dosis antibiótica se realiza por la noche. En aquellos pacientes en los que se ha realizado profilaxis durante 6 meses, y una vez suspendida ésta, presentan de nuevo infecciones sintomáticas, puede reiniciarse la profilaxis prolongándola durante 102 años. ${ }^{37,38}$

Como alternativa a los antibióticos o a los estrógenos tópicos, en pacientes reacios a tomarlos 0 en los que fracasa la profilaxis, puede administrarse extracto de arándano rojo en forma de comprimidos. ${ }^{37}$ No obstante, la dosificación no está bien establecida y estudios recientes indican que el zumo de arándanos es menos efectivo en la prevención de IU recurrentes de lo que previamente se había creído. ${ }^{39}$ 
Tabla 6. Regímenes de profilaxis antimicrobiana para IU recurrente

\begin{tabular}{|l|l|l|}
\hline Antibiótico & Profilaxis continua* $^{*}$ & Profilaxis postcoital \\
\hline Cotrimoxazol & $\begin{array}{l}40 / 200 \mathrm{mg} / \text { día ó } \\
40 / 200 \mathrm{mg}, 3 \text { veces/semana }\end{array}$ & $\begin{array}{l}40 / 200 \mathrm{mg} \text { ó } \\
80 / 400 \mathrm{mg}\end{array}$ \\
\hline Nitrofurantoína & $50-100 \mathrm{mg} / \mathrm{día}$ & 50 ó $100 \mathrm{mg}$ \\
\hline Cefalexina & $125-250 \mathrm{mg} / \mathrm{día}$ & $250 \mathrm{mg}$ \\
\hline Norfloxacino & $200 \mathrm{mg} /$ día & $200 \mathrm{mg}$ \\
\hline Ciprofloxacino & $125 \mathrm{mg} /$ día & $125 \mathrm{mg}$ \\
\hline Fosfomicina trometamol & $3 \mathrm{~g} / 10$ días & ---- \\
\hline
\end{tabular}

*Administración nocturna.

\section{Bibliografía}

1. Hernández-Burruezo JJ, Omar Mohamed-Balghata M, Aliaga Martínez L; Sociedad Andaluza de Enfermedades Infecciosas (SAEI). Urinary tract infections. Med Clin (Barc) 2007; 129(18): 707-15

2. Pigrau, C. Infecciones del trato urinario nosocomiales. Enferm Infecc Microbiol Clin 2013. http: //dx.doi.org/10.1016/..eimc.2012.11.015

3. García Viejo MA, Noguerado Asensio A; Grupo de Trabajo de las Infecciones Urinarias del Grupo de Trabajo de Enfermedades Infecciosas (GTEI) de la Sociedad Española de Medicina Interna. La Infección del tracto urinario en los servicios de medicina interna. Rev Clin Esp 2010; 210(11): 537-544

4. C. Pigrau, J.P. Horcajada, J. Palou, M. Pujol. Infección urinaria. En: JM. Aguado, J Fortún, editores. Protocolos clínicos en Enfermedades Infecciosas. Sociedad Española de Enfermedades Infecciosas y Microbiología Clínica (SEIMC). Madrid; 2007. p 151-183.

5. Mensa J, Gatell JM, García-Sánchez JE, Letang E, López-Suñé E, Marco F, editores. Guía de terapéutica antimicrobiana.23a ed. Barcelona: Escofet; 2013.

6. Gupta K, Trautner, B. In the clinic. Urinary tract infection. Ann Intern Med 2012; 156(5): ITC3-1.

7. Schollum JB, Walker RJ. Adult urinary tract infection. Br J Hosp Med (Lond) 2012 73(4):218-23.

8. Hooton TM. Uncomplicated urinary tract infection. N Engl J Med 2012; 366(11) 1028-37.

9. Andreu A, Cacho J, Coira A, Lepe JA. Diagnóstico microbiológico de las infecciones del tracto urinario. Enferm Infecc Microbiol Clin 2011; 29(1): 52-57.

10. A. Andreu Domingo, J. Cacho, A. Coira Nieto, J.A. Lepe Jiménez. Diagnóstico microbiológico de las infecciones del tracto urinario. En: Emilia Cercenado, Rafael Cantón, editores. Procedimientos en Microbiología Clínica. Recomendaciones de la Sociedad Española de Enfermedades Infecciosas y Microbiología Clínica (SEIMC). $2^{a}$ edición (14a), 2010. www.seimc.org/documentos/protocolos/microbiologia.

11. Kauffman CA, Fisher JF, Sobel JD, Newman CA. Candida urinary tract infectionsdiagnosis. Clin Infect Dis 2011; 52(S6): S452-S456.

12. Palou J, Pigrau C, Molina I, Ledesma JM, Angulo J. Etiología y sensibilidad de los uropatógenos identificados en infecciones urinarias bajas no complicadas de la mujer (estudio ARESC): implicaciones en la terapia empírica. Med Clin (Barc) 2011; 136(1): 1-7.

13. Tena D, González- Praetorius A, González JC, Heredero E, Illescas S, Sáinz de Baranda $\mathrm{C}$ et al. Evolución del patrón de sensibilidad de Escherichia coli en infecciones del tracto urinario diagnosticadas en la comunidad durante el período 2003-2007. Estudio multicéntrico en Castilla la mancha. Rev Esp Quimioter 2010; 23(1): 36-42.

14. Monroy C, Mañas MD, Santamaría A, Clemente MI. Resistencia antibiótica en la infección del tracto urinario e identificación de los factores de riesgo asociados. Rev Clin Esp 2010; 2010(11):589-90.

15. Díaz MA, Hernández-Bello JR, Rodríguez-Baño J, Martínez-Martínez L, Calvo $J$, Blanco $\mathrm{J}$ et al. The diversity of Escherichi coli producing extended-spectrum $\beta$-lactamases in Spain: second nationwide study. J Clin Microbiol 2010; 48(8): 2840-5.

16. Ruiz de Alegría C, Rodríguez-baño J, Cano ME, Hernández Bello JR, Calvo J, Román $E$ et al. Klebsiella pneumoniae producing extended-expectrum $\beta$-lactamases in Spain: microbiological and clinical features. J Clin Microbiol 2011; 49(3): 1134-6.

17. Pitout JD. Infections with extended-spectrum $\beta$-lactamase-producing Enterobacteriaceae. Changing epidemiology and drug treatment choices. Drugs 2010; 70(3): 313-333.

18. Rodríguez-Baño J, Navarro MD, Retamar P, Picón E, Pascual Á. $\beta$-lactam/ $\beta$-lactam inhibitor combinations for the treatment of bacteremia due to extended-spectrum $\beta$-lactamase-producing Escherichia coli: a post hoc analysis of prospective cohorts. Clin Infect Dis 2012; 54(2): 167-74.
19. Sobel JD, Kaye D. Urinary tract infections. En: Mandell GL, Benett JE, Dolin R, editors. Mandell, Douglas and Benett's principles and practice of infectious diseases. 7 th ed. Vol 1.Philadelphia: Churchill Livingston; 2010.p. 957-985.

20. Dielubanza EJ, Schaeffer AJ. Urinary tract infections in women. Med Clin N Am 2011; 95(1): 27-41.

21. Benway BM, Moon TD. Bacterial prostatitis. Urol Clin N Am 2008; 35: 23-32.

22. Wilson ML, Gaido L. Laboratory diagnosis of urinary tract infections in adult patients. Clin Infect Dis 2004; 38(8):1150-8.

23. Raynor MC, Carson CC 3rd. Urinary infections in men. Med Clin N Am 2011; 95(1): 43-54.

24. Leisure ML, Dudley SM, Donowitz LG. Does a clean-catch urine simple reduce bacterial contamination? N Engl J Med 1993; 328(4):289-90.

25. De Cueto M. Diagnóstico microbiológico de la infección del tracto urinario. Enferm Infecc Microbiol Clin 2005;23 Suppl 4:9-14.

26. Ifergan J, Pommier R, Brion MC, Glas L, Rocher L, BellinMF. Imaging in upper urinary tract infections. Diagn Interv Imaging 2012; 93(6): 509-19.

27. Gupta K, Hooton TM, Naber KG, Wullt B, Colgan R, Miller LG et al. International clinical practice guidelines for the treatment of acute uncomplicated cistitis and pyelonephritis in women: a 2010 update by the Infectious Diseases Society of America and European Society for Microbiology and Infectious Diseases. Clin Infect Dis 2011; 52(5): e103-e120.

28. Naber KG, Wullt B, Wagenlehner FM. Antibiotic treatment of uncomplicated urinary tract infection in premenopausal women. Int J Antimicrob Agents 2011; 38 Suppl:21-35.

29. Wagenlehner FM, Wullt B, Perletti G. Antimicrobials in urogenital infections. Int J Antimicrob Agents. 2011; 38 Suppl:3-10.

30. Pallet $A$, Kieran $H$. Complicated urinary tract infections: practical solutions for the treatment of multiresistant Gram-negative bacteria. J Antimicrob Chemother 2010; 65 Suppl 3: iii25-33.

31. Coelho RF, Scheneider-Monteiro ED, Mesquita JL, Mazzucchi E, Marmo Lucon A, Srougi M. Renal and perinephic abscesses: analysis of 65 consecutive cases. World J Surg. 2007; 31 (2): 431-6.

32. Meng VM, Layla AM, McAninch JW. Current treatment and outcomes of perinephric abscesses. J Urol 2002; 168 (4 Pt 1):1337.

33. Dembry LM, Andriole VT. Renal and perirenal abscesses. Infect Dis Clin North Am 1997; 11 (3): 663-680.

34. Ubee SS, McGlynn L, Fordham M. Emphysematous pyelonephritis. BJU Int 2011; 107(9): 1474-78

35. Huang JJ, Tseng CC. Emphysematous pyelonephritis: clinicoradiological classification, management, prognosis, and pathogenesis. Arch Intern Med 2000; 160(6): 797-805.

36. Pewitt Eb, Schaeffer JS. Urinary tract infection in Urology, including acute and chronic prostatitis. Infect Dis Clin North Am 1997; 11(3):623-46.

37. Pigrau-Serrallach $\mathrm{C}$. Infecciones urinarias recurrentes. Enferm Infecc Microbiol Clin 2005; 23(Supl. 4): 28-39

38. Lichtenberger P, Hooton TM. Antimicrobial prophylaxis in women with recurrent urinary tract infections. Int J Antimicrob Agents. 2011; 38 Suppl: 36-41.

39. Jepson RG, Williams G, Craig JC. Cranberries for preventing urinary tract infections. Cochrane Database Syst Rev 2012; 10:CD001321. 